\title{
Flashback Avoidance in Swirling Flow Burners
}

\section{Impedimento de reflujo de llama en quemadores de flujo giratorio}

\author{
Vigueras-Zúñiga Marco Osvaldo \\ Universidad Veracruzana, México \\ Facultad de Ingeniería \\ E-mail:mvigueras@uv.mx \\ Valera-Medina Agustín \\ Cardiff University \\ School of Engineering, United Kingdom \\ E-mail:Valeramedinaa1@cardiff.ac.uk
}

\author{
Syred Nicholas \\ Cardiff University \\ School of Engineering, United Kingdom \\ E-mail:nsyred@cf.ac.uk \\ De la Rosa-Urbalejo Daniel \\ Cardiff University \\ School of Engineering, United Kingdom \\ E-mail:delarosaurbalejod@cardiff.ac.uk
}

Information on the article: received: May 2013, accepted: August 2013

\begin{abstract}
Lean premixed combustion using swirling flows is widely used in gas turbines and combustion. Although flashback is not generally a problem with natural gas combustion, there are some reports of flashback damage with existing gas turbines, whilst hydrogen enriched fuel blends cause concerns in this area. Thus, this paper describes a practical approach to study and avoid flashback in a pilot scale $100 \mathrm{~kW}$ tangential swirl burner. The flashback phenomenon is studied experimentally via the derivation of flashback limits for a variety of different geometrical conditions. A high speed camera is used to visualize the process and distinguish new patterns of avoidance. The use of a central fuel injector is shown to give substantial benefits in terms of flashback resistance. Conclusions are drawn as to mitigation technologies.
\end{abstract}

\section{Resumen}

El uso de flujos giratorios en condiciones pobres premezcladas se utiliza ampliamente en turbinas de gas y en combustión en general. A pesar de que el reflujo de llama no suele ser un problema durante la combustión de gas natural, existen muchos reportes sobre el daño que el reflujo puede producir en turbinas de gas actuales, especialmente cuando se utilizan mezclas de combustible con hidrógeno enriquecido. Por ende, este artículo describe una aproximación práctica al estudio y eliminación del reflujo de llama en un quemador de flujo giratorio tangencial de $100 \mathrm{~kW}$. El fenómeno de reflujo de llama se estudia experimentalmente mediante la derivación de los límites de reflujo para una gran variedad de geometrías diferentes. Se utilizó una cámara de fotografía rápida para visualizar el proceso y distinguir algunos parámetros para evitar el fenómeno. El uso de un inyector de combustible central produjo beneficios substanciales en términos de resistencia al reflujo de llama. Se presentan conclusiones sobre cómo mitigar el fenómeno.

\section{Keywords:}

- flashback

- swirling flows

- high speed photography

\section{Descriptores:}

- reflujo de llama

- flujos giratorios

- fotografía de rápida velocidad 


\section{Introduction}

The crucial feature of swirl burners is the formation of a central recirculation zone (CRZ) which extends blow off limits by recycling heat and active chemical species to the root of the flame in the burner exit. However, unless its size and shape are properly controlled, problems can arise. The CRZ can, for instance, readily extend back into the burner, even surrounding the fuel injector and facilitating early flashback (Subramanya and Choudhuri, 2007; Thornton et al., 2007; Lieuwen et al., 2008).

Flashback can occur when the gas velocity becomes lower than the flame speed, allowing the flame to propagate upstream, potentially causing damaging effects. The phenomenon can be caused by (i) boundary layer flame propagation, (ii) turbulent flame propagation in the core flow, (iii) combustion instabilities and (iv) upstream flame propagation of coherent vortical structures (Lieuwen et al., 2008, Lefebvre, 1999). For the latter, flow speed not necessarily can be lower than the flame velocity everywhere, though flashback is still observed. This refers to a highly complex phenomenon. This paper focuses on the two main causes of flashback:

- Flashback occurring through the low-velocity flow in the boundary layer along the walls of the burner close to the exit and governed by the critical boundary velocity gradient,

- Flashback occurring due to coherent structures.

The mechanisms may involve the use of homogeneous and/or heterogeneous reactions. Lieuwen et al. (2008) reviewed flashback in the context of syngas fired combustors and noted that minimization of flashback requires that the flow field should not have strong local velocity deficits and the axial flow velocity must be substantially above the local turbulent flame speed, $S_{t}$. High turbulence levels, one of the very useful features of swirling flow because of their mixing potential, detrimentally affect flashback limits due to their effects on $\mathrm{S}_{\mathrm{t}^{\prime}}$ especially for hydrogen enriched syngases.

Lean combustion tends to reduce flame velocity, but other factors associated with engine cycles, such as high temperatures, pressure, turbulence levels and preignition reactions in the gases due to appreciable residence times at high temperature cause increased flame speeds, encouraging flashback.

With swirl burners, the swirl number, S (Syred and Beer, 1974) defined by the normalized ratio of axial flux of axial momentum and axial flux of angular momentum, is crucial as higher values $(S>1.2)$ tend to exacer- bate the formation of excessively large CRZs which extend back into the burner. Moreover, higher swirl numbers tend to increase turbulence and consequently, the turbulent flame speed (Valera et al., 2011; Huang and Yang, 2004; 2005) and propensity to flashback in low velocity regions. Combustion located downstream of the tangential inlets alters significantly the axial flux of axial momentum Syred and Beer, 1974) hence local swirl number is also affected. This effect depends strongly on the equivalence ratio, rate of heat release, location of flame front and mode of fuel injection. Such changes in swirl number due to combustion can subsequently alter the resistance to flashback. Off-design condition operations that impact on the swirl number and flame stability can produce oscillations associated with unsteady flashback (Dhanuka et al., 2009).

These factors can explain the anomalous behavior of many swirl burners under various conditions, including flashback. Premixed combustion can especially change a highly swirling flow from a situation with a large stable CRZ to one where the CRZ is eliminated, the effect being a maximum at an equivalence ratio, $\phi$, $\sim 1$ where heat release is at its highest point. Varying the equivalence ratio can substantially affect the occurrence, strength and size of any CRZ formed. Therefore, the evidence suggests that flashback is very dependent on several parameters, making very difficult to generalize any pattern that directly influence this phenomenon.

Flame flashback from the combustion chamber into the mixing zone can limit the reliability of swirl stabilized lean premixed combustion in gas turbines. A phenomenon labelled combustion induced vortex breakdown (CIVB) has been identified as an initial flashback mechanism in some swirl burners (Kröner et al., 2003; Kiesewetter et al., 2007; Kröner et al., 2007). It occurs with values of $S$ between 0.5 and 0.9 when vortex breakdown is about to, or has just occurred (Gupta et al., 1984), without the presence of a central fuel injector. The phenomenon occurs as a sudden transition driven by the interaction of chemical reactions and vortex dynamics. First, a CRZ forms downstream of the burner exit that holds the flame. Then, the chemical reactions in the vortex core lead to the propagation of the CRZ into the burner. A closed recirculation bubble forms and the drop of density leads to the extinction of the downstream CRZ (Kröner et al., 2007). Lieuwen et al. (2008) also indicated that the CIVB phenomenon is primarily determined by density gradients and other combustion aerodynamic phenomena. Syred and Beer (1974) and Gupta et al. (1984) showed that these effects can be caused by swirl number re- 
duction effects as combustion effects increase the axial flux of axial momentum, but generally not that of angular momentum. For instance with the burner used in this study and for equivalence ratios $\sim 1$ the CRZ can completely disappear, whilst an equivalence ratio reduction to about $\sim 0.75$ leads to vortex breakdown and the formation of a CRZ in the burner exit region (Valera et al., 2011).

Flashback depends on parameters such as heating values, reaction rate, etc., making more difficult the use of potential alternative fuels (Chiesa et al., 2005; Bagdanavicius et al., 2009). Some authors (Huang and Yang, 2004; Dhanuka et al., 2009) have experimented with $\mathrm{CO} 2$ and $\mathrm{N} 2$ diluents to control flame propagation for these fuels.

Another important parameter in flashback propagation is the geometry of the system (Plee and Mellor, 1978). Small changes in the details of the geometry of the premixing tube such as steps, diverging sections, surface discontinuities, or method of fuel injection such as counterflow injection, diffusive penetration, etc., can cause significant changes in flashback behaviour.

At values of $S>1$ the flame and at least part of the CRZ will extend naturally and attach to the burner baseplate as a long columnar tulip shaped structure Syred and Beer, 1974; Lucca and O'Doherty, 2001), the bulbous end of the tulip being located in the burner exit. When a fuel injector is fitted, the columnar CRZ (and flame burning on its boundary) may surround the injector, unless the injector is of large diameter (Kiesewetter et al., 2007) or $S$ is reduced. The CRZ size and position can become variable in the region of the injector as equivalence ratio is reduced and the aerodynamics tend more to that of the isothermal state, remembering that combustion can reduce $S$ to such an extent that the CRZ disappears Syred and Beer, 1974); Valera et al., 2011) due to the effects of varying density ratios.

The effect of Reynolds number (Re, normally based on isothermal conditions and the average throat axial velocity) on vortex breakdown and the formation of CRZs must also be considered. Sarpkaya (1971) showed the effect of Re on the location of vortex breakdown, the precursor to the formation of CRZs. Essentially it was only for $S>1$ that the CRZ would firmly locate to the baseplate of the swirl generator; otherwise it was freely located. The effect was also complicated by the transition between different types of vortex breakdown (Lucca and O'Doherty, 2001). Lucca-Negro and O'Doherty (2001) showed that although other workers identified other forms and occurrences of vortex breakdown, the dependence of its location upon Reynolds numbers was still very similar to Sarpkaya's. Of relevance to swirl combus- tion is that for $0.6<\mathrm{S}<1.1$ where the vortex breakdown, hence any CRZ, was not attached to the baseplate of the swirl generator for any Reynolds number.

From the above the main effects on swirl combustion and especially flashback are:

- $\quad$ CRZs generated by values of $S$ between 0.5 and 1.0 are desirable as associated flames are located away from vulnerable surfaces, whilst pressure drop is minimized. However the CRZs are likely to be easily perturbed by coupling with acoustic or combustion induced disturbances due to their 'free' axial location.

- Devices operating at higher Reynolds numbers may behave differently close to flashback as the onset of vortex breakdown may well subtly alter. Although chemical reactions rate dependency on pressure is important with CIVB propagation (and especially any hydrogen containing fuel), the strength of the initial vortex breakdown and CRZ is highly related to Re (Sarpkaya, 1971) especially with natural gas where flashback can occur at low exit velocities, as discussed later. Reynolds number effects on vortex breakdown, CRZ formation, flame stability and hence flashback especially for smaller burners or those operating at high turndown, are important as the isothermal Reynolds number readily reduces with combustion by up to a factor $\sim 8$ (at 1000K) to 16 (at 1500K) (Sarpkaya, 1971).

- Central fuel injectors, widely employed especially with liquid fuels, will interact and interfere with the above processes, although it is recognized that CRZs can easily surround smaller injectors and promote early flashback, especially at lean values of $\phi$ and values of $\mathrm{S}>1$ (Lucca and O'Doherty, 2001; Syred, 2006).

This paper is thus aimed at analyzing the mechanisms of flashback taking place in a natural gas fired swirl burner with and without a central fuel injector so as to understand the physical processes and how they can be alleviated using different passive mechanisms.

\section{Experimental setup}

Experiments were performed in a $100 \mathrm{~kW}$ steel scaled version of a $2 \mathrm{MW}$ commercial swirl burner under combustion conditions, Figure 1.

Two tangential inlets were used together with inserts blocking $25 \%$ of their transversal area, giving a swirl number of 1.08 (0.86 with the nozzle, Figure 2 fitted) (Valera et al., 2009; Valera, 2009). 




Figure 1. Details of swirl burner

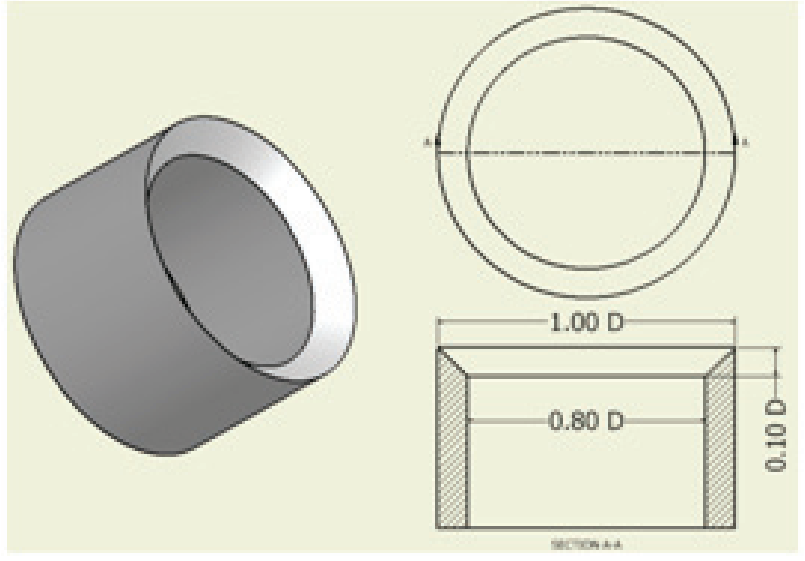

Figure 2. Quarl nozzle

Flow straighteners consisting of a honeycomb matrix were fitted upstream of each inlet. The system was fed by a centrifugal fan providing air flow via flexible hoses and two banks of rotameters for the control of the air flow and injection of the natural gas respectively. The inclusion of two stainless steel mirrors at the exit and bottom of the rig (and rotated by $45^{\circ}$ ) allowed the visualization of flashback. A quartz plate replaced the burner baseplate to enable visualization of flashback that occurred inside of the swirl chamber when using high speed photography. The plate was mounted via an extension to the base of the burner to remove the quartz plate from the flashback region. This was observed not to affect the flashback process.

Two different modes of natural gas injection were possible, a diffusive mode with fuel injected along the central axis from the burner baseplate and a premixed mode with entry in one or both tangential inlets, located before the inserts used to regulate the Swirl number. Premixed gas injectors, extending across the inlet ducts, were located just before the inlets. Turbulence is generated by the ducts which cross the inlet area and increase the mixing previous to the entrance of the mixture into the swirl chamber. Overall equivalence ratio, $\phi$, with $5 \%$ uncertainty due to the variations in the air and gas flows is reported, as well as the fuel proportion injected diffusively by the fuel injectors mounted along the axis followed by that injected as premixed in the tangential inlets. The following nomenclature was used to describe the relative quantities of fuel injected diffusively either through the center of the baseplate or via the fuel injector and premixed through injectors upstream of the tangential inlets: i.e., $\{25-40\}$ means that $25 \_1 / \mathrm{min}$ was injected diffusively, $40 \_1 /$ min premixed. To modify $\phi$, the air supply was kept constant during the test whilst varying the gas supply until flashback was observed. The experimental conditions are at $288 \mathrm{~K}$ and sea level atmospheric pressure.

A Photron Fastcam high speed camera model APX RS of 250,000frames/s maximum speed was used for flashback visualization with a $105 \mathrm{~mm}, 1: 2.8$ Nikon Lens. The camera was setup at only 500frames/s to avoid resolution problems and increase the visual field, since the frequency of the expected events and of the large coherent structures known to be present in the system has been observed to lie in the range of 100$200 \mathrm{~Hz}$ (Valera, 2009; Nauert et al., 2007). The resulting images were analyzed using the PFV version 2.4.1.1 software. It is recognized that the use of these technique gives insight of the mechanism of propagation of the flame, but not a full picture of the intensity of the combustion process. The appearance of soot particles can degrade the unfiltered images, whilst the view of reaction occurring in the boundary layers near the walls is attenuated due to the presence of dark walls in the field of view.

Equivalence ratios were investigated from lean conditions at 0.600 to rich values at 2.000 . A wide variation in the airflow and gas flow rates was also made to visualize the progressive development of flames and coherent structures.

The burner exit was varied from an open case with no nozzle to that with a quarl nozzle (Figure 2). Corresponding swirl numbers are 1.08 and 0.86 respectively (Valera et al., 2011).

The central fuel injector extended from the burner baseplate to near the nozzle (Figure 2). This was $35 \mathrm{~mm}$ outer and $23.4 \mathrm{~mm}$ inner diameters, whilst its end was located $47.5 \mathrm{~mm}$ upstream from the burner exit. The nozzle extending into the swirl chamber is designed to reduce flashback by increasing the radial velocity. It was originally developed for a larger scale $2 \mathrm{MW}$ ver- 
sion of this unit (Syred, 2006). All reported flashback curves were measured with a steel baseplate fitted and the cage and quartz plate removed. For the cases with partially premixed combustion and no injector, fuel was simply fed at low velocity through a nozzle in the center of the baseplate.

First experiments were made with no confinement attached to the combustion chamber. However, as most practical flames do not discharge into free air, for much of the work, confinements from previous experiments (Syred, 2006; Valera et al., 2009) were used, with open and conical exit nozzles, the latter being the most representative of industrial burners (Figure 3).

The objective was to recognize the position and evolution of flashback, as a function of different geometries and parameters which are known to be influential (Valera et al., 2011; 2009). Geometrical variables included the effect of a fuel injector, nozzle, two different confinements, with both premixed and partial premixed combustion being also investigated.

\section{Results and discussion}

The phenomena of flashback was investigated as a function of a wide range of variables for natural gas combustion including equivalence ratio, velocity levels, geometrical parameters including nozzles, confinements and fuel injectors. Comparison between cases was performed using both the averaged (isothermal) axial velocities in the burner exit and the tangential inlet velocity as follows:

- $\mathrm{V}_{\mathrm{ex}}=1.219 \mathrm{~W}$

- $\mathrm{V}_{\text {exqua }}=1.9 \mathrm{~W}$

- $\mathrm{W}=$ inlet flow rate/tangential inlet area

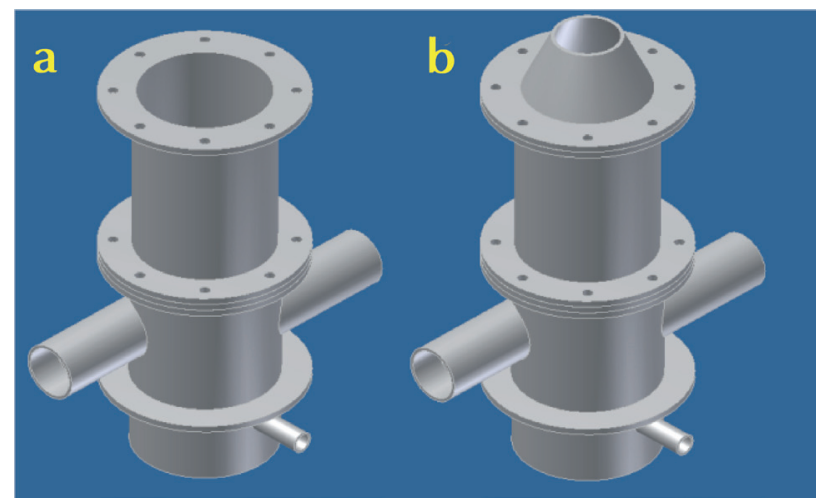

Figure 3. Burner confinements a) open and b) conical exit geometries

\section{Characterization process}

A wide range of flashback conditions were investigated for cases with and without confinement, injector and nozzle. Either $100 \%$ premixed combustion or partially premixed combustion was used. For each run stable conditions were established for a given air flow and then the equivalence ratio was varied until flashback occurred. The flashback condition was established when the flame moved upstream towards the mixing chamber, accessing the latter. This was monitored using the high speed camera. The burner was then cooled at high airflow before proceeding with the next test. To trigger the high speed camera whilst obtaining flashback conditions, the system was set up at conditions close to flashback with premixed combustion with extra small quantities of diffusive fuel. To initiate flashback the diffusive fuel was then switched off (not being redirected to the premixed inlets), providing consistency for the visualization process.

Flashback with no fuel injector, premixed combustion

Figure 4 shows a comparison of flashback conditions for the burner with various geometrical configurations, but no central fuel injector. Best flashback limits are obtained with no confinement or nozzle for most equivalence ratios (Figure 4a). Comparing Figures $4 \mathrm{~b}$ and $4 a$ the nozzle only shows flashback benefit for values of $\phi \leq 0.7$. However, flashback resistance seems to be worsened by the increased strength of the CRZ, as observed by Valera-Medina (2009). The use of the nozzle increases the CRZ, which seems to be affecting the flashback resistance limit. Moreover, Figures $4 \mathrm{c}$ and $4 \mathrm{~d}$ show that the confinement with or without the nozzle increases susceptibility to flashback for all values of $\phi$ (Bagdanavicius et al., 2009).

In the case of the confinement, the change in flashback limits is due to reduced external air entrainment and its cylindrical shape which produces changes in axial and radial pressure gradients, thus modifying aerodynamic characteristics. Such aerodynamic changes have been observed under both isothermal and combustion conditions (Syred, 2006; Valera et al., 2009). The flashback line is also steeper with confinement, (compare Figure $4 \mathrm{~b}$ to $4 \mathrm{c}$ ) and extends to higher velocities for $\phi \geq 0.75$. Results were only obtainable up to $\phi=0.8$ with the confinement due to rig limitations, although the trends are clear. 

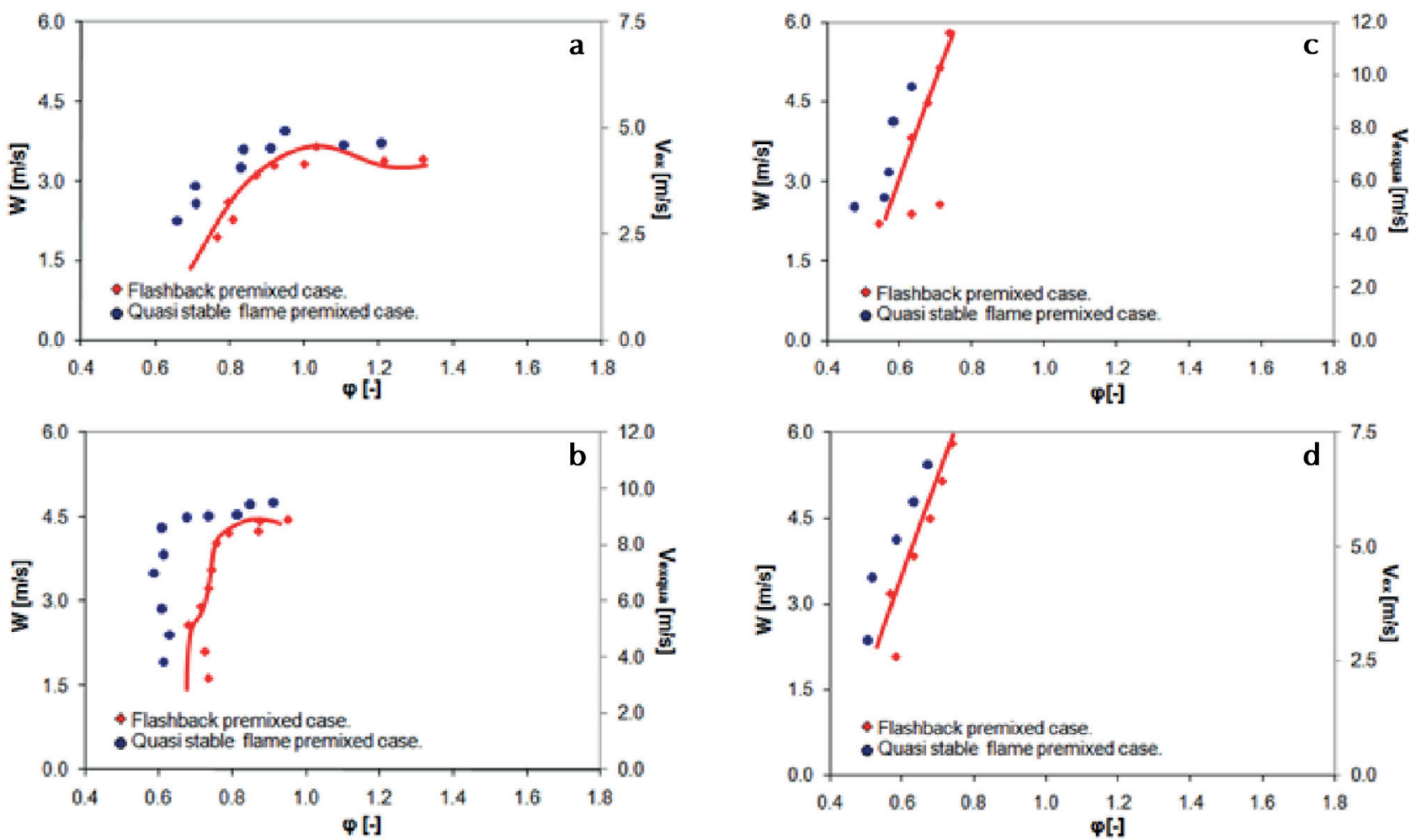

Figure 4. Flashback comparison without fuel injector. Confinement as in Figure 3a, a) no confinement-without nozzle, b) no confinementnozzle, c) confinement-nozzle, d) confinement-without nozzle

Comparison of Figures $4 \mathrm{c}$ and $4 \mathrm{~d}$ shows the dominant effect of the confinement upon flashback as there appears to be little effect of the nozzle. Due to the changes in the aerodynamics that affect the CRZ, the use of confinement alters the strength of the recirculation zone, changing the flashback trend. Other studies (Valera, 2009; Nauert et al., 2007) show that confinement augments the CRZ strength, thus confirming that flashback resistance decrement is related to alterations of this structure.

Observations of flashback with the open flame and no confinement showed that just before flashback initiation the flame front was of thin annular form and was located on the burner lip, whilst the resulting flame coalesced a couple of diameters downstream, then being of long lazy form. The flame could be observed to be trying to move down the outer wall boundary layer and was attempting to propagate in this mode. This led to the conclusion that boundary layer flame propagation was part of the way in which the flame flashed back.
Flashback with the fuel injector, premixed combustion

Figure 5 shows three flashback curves with the fuel injector. The improvements in flashback occurrence are very clear and emphasize the advantages of the use of the injector for all cases.

Differences between two sets of curves, Figures $5 \mathrm{a}$ and $5 \mathrm{~b}$, are small with the nozzle, with or without the confinement. Figure $5 \mathrm{c}$ with the confinement and no nozzle shows flashback limits that are somewhat worsened, occurring at velocities about $10 \%$ higher. Nevertheless, the trend is consistent. The increase in flashback resistance is produced by the presence of the injector, which avoids the direct influence of the CRZ, probably with the avoidance of the formation of the CIVB. Comparing Figures 4 and 5, the changes in aerodynamics above the injector are no longer a determinant factor in the flashback limit. This leaves the entire phenomenon to the boundary layer propagation. Moreover, a core 

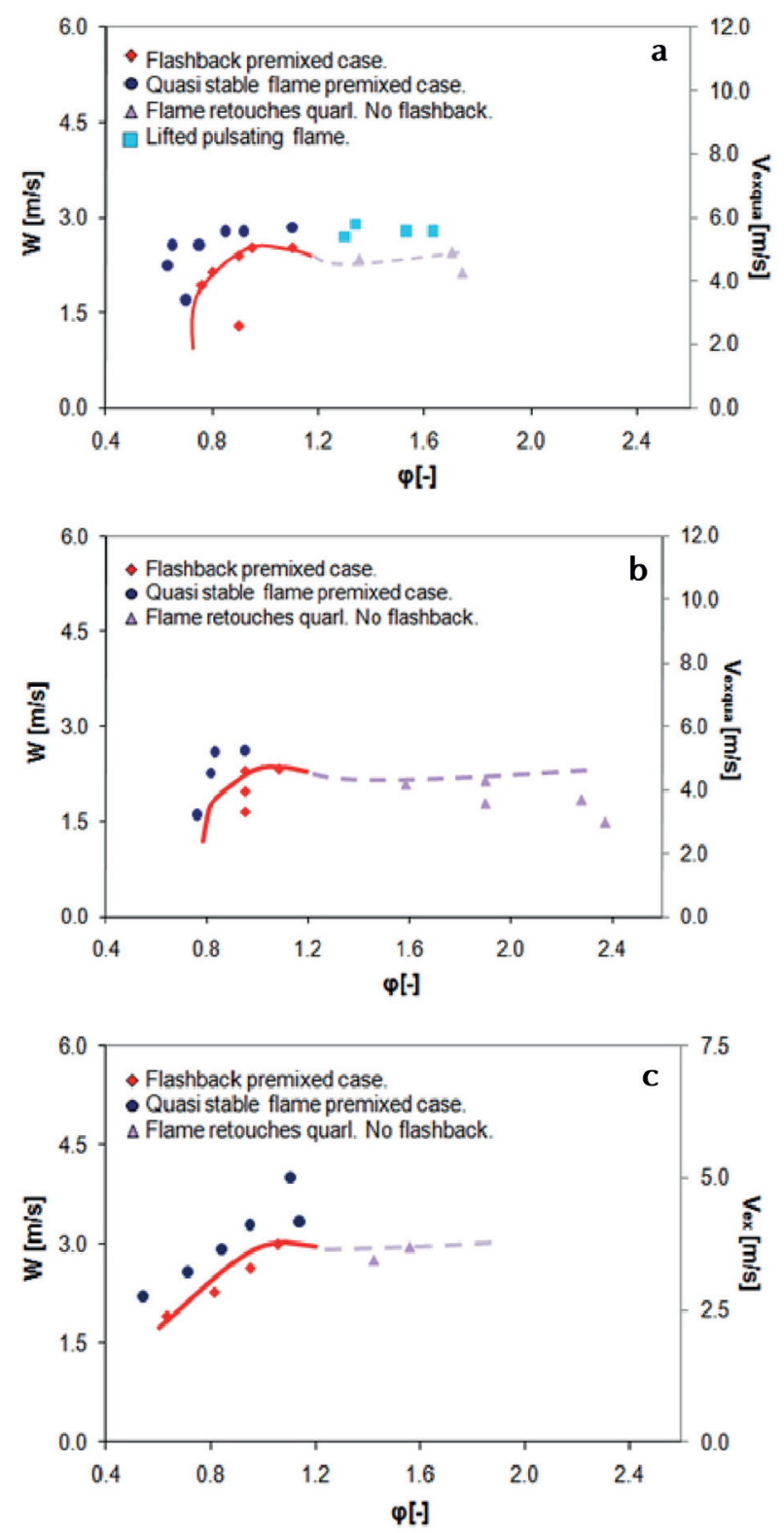

Figure 5. Flashback results with fuel injector. Confinement as in Figure 3a, a) no confinement-nozzle, b) confinement-nozzle, c) confinement-without nozzle

flow acceleration induced by the injector increases flow velocities in the annular flow surrounding the latter, hence boundary layer velocity gradients in the outer wall boundary layer are augmented with flashback resistance.

The flame with the injector would also re-attach to the nozzle for rich equivalent ratios, an effect of the changes in flame front location, occurrence and form of any CRZ. There appears to be a transition from the state with flashback for equivalence ratios less than about 1.05 to that with the flame attached to the lip of the nozzle. Flashback always occurred soon after two flame fronts formed, one located in the core flow, the other on the outer burner lip

As discussed earlier, flashback was more intense with the injector for all cases tested. This occurs because velocity levels at flashback are lower in the system by up to a factor of 2 for a given equivalence ratio, compare Figures 4 and 5. The fitting of the fuel injector has thus substantially improved flashback limits.

An interesting phenomenon developed from low to intermediate $\operatorname{Re}(\sim 15,000$ to 26,000$)$ around values of $\phi \sim 1.1$ to 1.2. The flame would attach to the nozzle, then move in, down the boundary layer, and then out of the nozzle around the injector. At this point the flame was incapable of flashback through the boundary layer or indeed stabilizing in the shear flow between the nozzle and fuel injector as velocity gradients were too high. When an equivalence ratio of 1.1 was reached, the flame located inside of the sleeve in the boundary layer around the injector. There was no reaction in the annulus between the outer flame at the wall and the inner flame stabilized close to the swirl chamber. Under these conditions the flame would not flashback into the swirl chamber. At an equivalence ratio of 1.19 the flame moved back out of the burner and located on the lip of the nozzle. Boundary layer propagation seems to be the leading mechanism of flashback with the injector for lean equivalence ratios. However, the phenomenon of boundary layer propagation towards the swirling flow is also altered by the stoichiometry of the flame and the velocity of reaction. Since the natural gas has a relatively slow burning velocity, the increase of mass flow rate (air and gas) produced a faster flow than the boundary layer propagation at high equivalence ratios, thus pushing back the flame towards the tip of the injector. This phenomenon was observed with both the open and the quarl nozzle (Figure 2). A summary of all premixed combustion cases is shown in Table 1.

\section{Visualization of the flow}

The process of flashback was visualized with high speed photography and results from the two cases with and without the injector are shown from Figures 6a to 61 . Figures $6 \mathrm{~b}$ to $6 \mathrm{f}$ show a sequence of images from the camera via a top view and the $45^{\circ}$ mirror with no fuel injector. The camera focuses only on the nozzle. Figure $6 a$ is a photo of the flame just before flashback and shows how the flame is attached to the burner lip with no combustion in the mid - section, $\phi=0.54$, the main 
Table 1. Summary of all cases with premixed combustion

\begin{tabular}{ccccl}
\hline Confinement & Injector & Nozzle & Swirl Number S & \multicolumn{1}{c}{ Observations } \\
\hline$\checkmark$ & $\checkmark$ & 1.08 & $\begin{array}{l}\text { Figura 4a. Typical flashback curve with a near stoichiometric } \\
\text { peak }\end{array}$ \\
$\checkmark$ & $\checkmark .86$ & $\begin{array}{l}\text { Figura 4b. Nozzle decreases flashback resistance. Stronger } \\
\text { CRZ visualized, possible responsible } \\
\text { Figura 4c. Confinement and nozzle decrease flashback } \\
\text { resistance substantially }\end{array}$ \\
& $\checkmark$ & 0.86 & $\begin{array}{l}\text { Figura 4d. Very similar to previous case, despite removal of } \\
\text { nozzle } \\
\text { Figura 5a. Typical flashback curve, with a near stoichiometric } \\
\text { peak, limits much improved due to Injector use }\end{array}$ \\
$\checkmark$ & $\checkmark$ & 0.86 & 0.86 & $\begin{array}{l}\text { Figura 5b. Flashback curve similar to previous case. } \\
\text { Confinement has little effect here on flashback } \\
\text { Figura 5c. Flashback curve somewhat worse than previous 2 } \\
\text { cases due to absence of nozzle }\end{array}$ \\
\hline
\end{tabular}

flame developing well downstream. At higher flow rates the flame was lifted and only reattaches to the burner lip close to flashback.

A sequence of flame images, from Figure $6 \mathrm{~b}$ to $6 \mathrm{f}$, shows how flashback is initiated. Figure $6 \mathrm{~b}$, besides illustrating the onset of combustion, shows the quartz baseplate with the dark blue image of the (not used) feed for the injector. Combustion is initiated in two regions in the outer wall region and boundary layer (Figure 6b). Combustion quickly propagates upstream and across the section of the nozzle, such that after 10 milliseconds it has spread to almost all the section of the nozzle, Figures $6 \mathrm{~b}$ to $6 \mathrm{f}$. With this configuration the flashback process is intermittent with flames darting up and down the wall boundary layer, often being stretched to extinction, not quite reaching the main swirl chamber and causing complete flashback. Interesting behavior occurred in the swirl chamber as the flame propagated radially outwards from the end of the nozzle to the tangential inlets (not shown). The process has a complex 2D propagation with the flames apparently following the inlet flow back to the inlets; simultaneously PVCs and small CRZs developed in the central region of flow, this is discussed in more detail elsewhere (Valera, 2009; Vigueras et al., 2012).

The process is quite different when the fuel injector is present, from Figures $6 \mathrm{~g}$ to $6 \mathrm{l}$. Figure $6 \mathrm{~g}$ shows the flame just before flashback, $\phi=0.95$. Two flame fronts are formed, one as before on the outer burner lip, the other in the center being stabilized by the fuel injector. Because of the higher value of $\phi$ and the presence of two flames it was not possible to visualize processes from the top view. The sequence of images shows flashback development via a bottom view through the quartz baseplate. The feed to the fuel injector obscures part of the view. In Figure 6h the quite uniform flame radiation from the burner exit is evident with combustion occurring in the wall boundary layers (green). Moving through the images flame propagation occurs radially outwards from the nozzle into the swirl chamber developing over a sector extending from $\sim 70^{\circ}$ to $150^{\circ}$. This process was not as intermittent as in the previous case and was much more violent owing to the higher values of $\phi$ and lower velocities due to the lower air flows. The flames rapidly and completely filled the swirl chamber to the tangential inlets in contrast to the case without the injector.

At low air flow rates boundary layer propagation is the leading mechanism of flashback. However, if the air-gas flow rate is high enough to overcome the propagation in the boundary layers of the sleeve and injector, flashback will not occur and the flame will be pushed back to the nozzle with a phenomenon of reattachment to the lip of the burner. This was corroborated using the high speed photography (Figure 7).

\section{Conclusions}

This paper describes a series of experiments for the analysis of flashback in a pilot scale swirl burner fired on natural gas. Several conclusions emerge:

1. When firing premixed natural gas the presence of a central fuel injector substantially improves resistance to flashback for the given swirl number range. This seems to be caused by flow acceleration in the central core flow affecting the outer wall boundary layer and the velocity gradients, added to the avoidance of the formation of any coherent structure through the burner passages. When no injector is present, the 


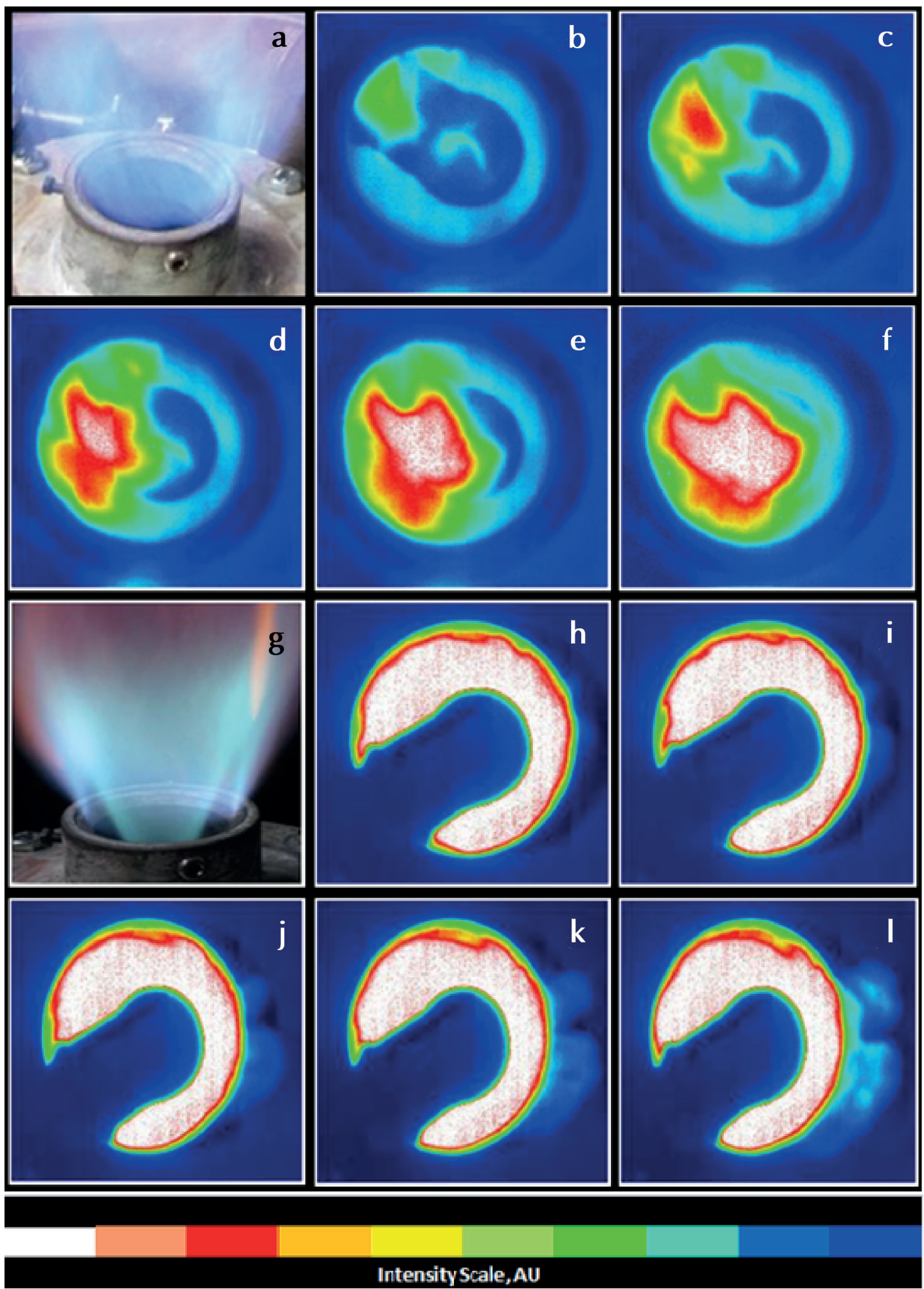

Figure 6. Flame and high speed camera images, a) top view, no injector with nozzle, 700_l/min air, $\phi=0.54$, flame just before flashback, $b$ to f) high speed camera images separated by 2 milliseconds showing flashback development, g) bottom view with injector and nozzle, $\phi=0.95, \mathrm{~S}=0.86, \mathrm{~h}$ to I) high speed camera images separated 2 milliseconds showing flashback expanding into the swirl chamber 

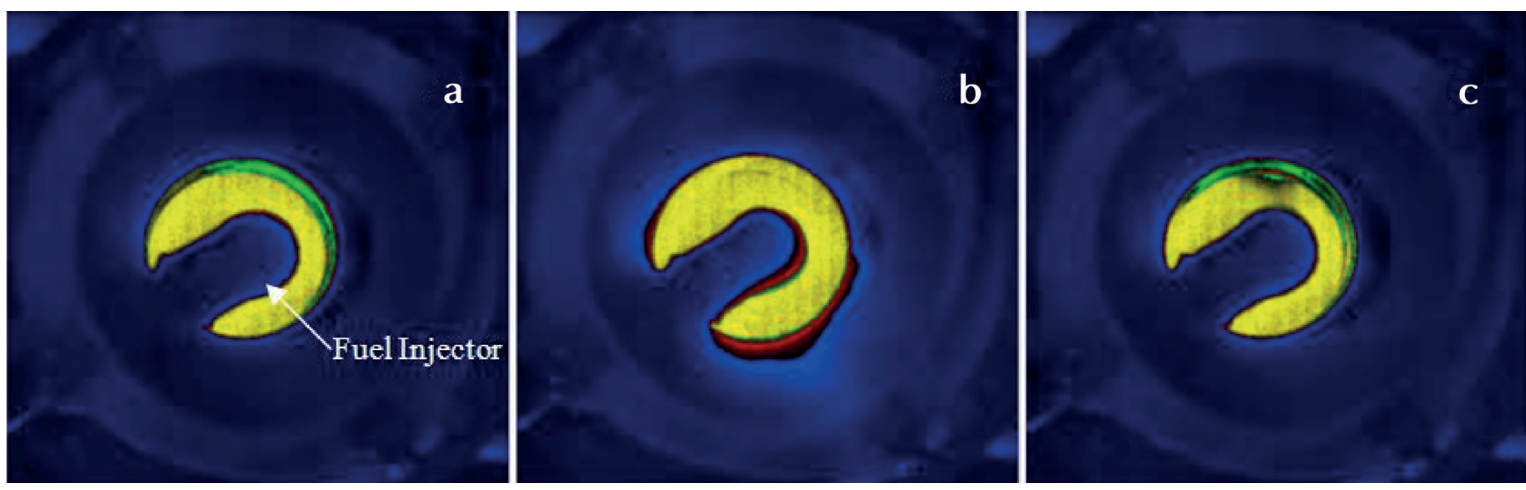

Figure 7. Case at $100 \mathrm{l} / \mathrm{min}$ gas, $100 \%$ premixed, a) the airflow is at $1,000 \mathrm{l} / \mathrm{min}$. The flame is attached to the nozzle, b) the airflow is at $900 \mathrm{l} / \mathrm{min}$. The flame is inside of the sleeve, close to flashback into the swirl chamber, c) the airflow is at $800 \mathrm{l} / \mathrm{min}$. The flame is reattached to the nozzle again, out of the sleeve

flow is generally of lower velocity across the flow section, coherent structures can propagate and hence the system is less able to resist flashback.

2. When no fuel injector was present, the nozzle and the confinements of Figure 3 worsened flashback. This is caused by changes in decay of tangential velocity profiles in the axial direction and elimination of external flow entrainment, which in turn alter the pressure gradients which govern CRZ formation/ strength and flame front location.

3. Flow visualization, flame characteristics and CFD indicate that no CRZs are present just before flashback without the injector. However, other experiments demonstrate the existence of a strong CRZ that influence the flame movement upstream, whilst others give details of coherent structures formed in the passages of the burner. Thus, the lack of CRZ just before flashback seems to be a point of transition that needs further research.

4. High speed photography showed that flashback started in a small area of the wall boundary of the burner exit and then rapidly spread across the nozzle as the flame propagated upstream.

5. The nozzle improved the flashback behavior by moving the flames further away from the injector and downstream of the burner exit with partially premixed injection. Different flow rates and equivalence ratios changed the position of the flame from being lifted to being attached prior to flashback; the CRZ that anchors the flame also moves axially in this process.

\section{Acknowledgements}

The authors gratefully acknowledge the Mexican Government (CONACYT) and the support of the Welsh As- sembly Government Low Carbon Research Initiative Programme, EPSRC (grant no EP/G060053) and the European Union via various grants.

\section{Nomenclature}

\begin{tabular}{|c|c|}
\hline Ae & Inlet area $\left[\mathrm{m}^{2}\right]$ \\
\hline CRZ & Central Recirculation Zone \\
\hline PVC & Precessing Vortex Core \\
\hline $\mathrm{R}_{\mathrm{e}}$ & $\begin{array}{l}\text { Reynolds number [-]. Here is defined using } \\
\text { average exit velocity and gas kinematic visco- } \\
\text { sity from the burner under isothermal con- } \\
\text { ditions }\end{array}$ \\
\hline $\mathrm{r}_{\mathrm{e}}$ & Exit radius of the burner $[\mathrm{m}]$ \\
\hline $\mathrm{r}_{\mathrm{i}}$ & $\begin{array}{l}\text { Radius upon which the tangential inlet jets } \\
\text { fire }[\mathrm{m}]\end{array}$ \\
\hline$S$ & $\begin{array}{l}\text { Geometrical Swirl number defined in the } \\
\text { text [-] }\end{array}$ \\
\hline$S_{t}$ & Turbulent Flame Speed [m/s] \\
\hline $\mathrm{V}_{\mathrm{ex}}$ & Exit velocity (axial), no nozzle $[\mathrm{m} / \mathrm{s}]$ \\
\hline$V_{\text {exqua }}$ & $\begin{array}{l}\text { Exit velocity (axial), with/without injector, } \\
\text { nozzle fitted }[\mathrm{m} / \mathrm{s}]\end{array}$ \\
\hline W & Tangential inlet velocity $[\mathrm{m} / \mathrm{s}]$ \\
\hline & Equivalence ratio [-] \\
\hline
\end{tabular}

\section{References}

Bagdanavicius A., Bowen P., Syred N., Kay P., Crayford A., Wood J. Burning Velocities of Alternative Gaseous Fuels at Elevated Temperature and Pressure, in: 47th AIAA Aerosp. Sci. Meet., Ref. AIAA-2009-0229, 2009.

Chiesa P., Lozza G., Mazzocchi L. Using Hydrogen as Gas Turbine Fuel. J. Eng. Gas Turbines Power, volume 127, 2005: 73-80. 
Dhanuka S.K., Temme J.E., Driscoll J.F., Mongia H.C. VortexShedding and Mixing Layer Effects on Periodic Flashback in a Lean Premixed Prevaporized Gas Turbine Combustor. Proc. Combust. Inst., volume 32 (issue 2), 2009: 2901-2908.

Gupta A.K., Lilley D.J., Syred N. Swirl Flows, Abacus Press, Tunbridge Wells, Kent, UK, 1984.

Huang Y. and Yang V. Bifurcation of Flame Structure in a LeanPremixed Swirl-Stabilized Combustor: Transition from Stable to Unstable Flame. Combust. Flame, volume 136 (issue 3), 2004: 383-389.

Huang Y. and Yang V. Effect of Swirl on Combustion Dynamics in a Lean Premixed Swirl Stabilized Combustor. Proc. Combust. Inst., volume 30 (issue 2), 2005: 1775-1782.

Kröner M., Fritz J., Sattelmayer T. Flashback Limits for Combustion Induced Vortex Breakdown in a Swirl Burner. J. Eng. Gas Turbines Power, volume 125 (issue 3), 2003: 693-700.

Kiesewetter F., Konle M., Sattelmayer T. Analysis of Combustion Induced Vortex Breakdown Driven Flame Flashback in a Premix Burner with Cylindrical Mixing Zone. J. Eng. Gas Turbines Power, volume 129 (issue 4), 2007: 929-936.

Kröner M., Sattelmayer T., Fritz J., Kiesewetter F., Hirsch C. Flame Propagation in Swirling Flows-Effects of Local Extinction on the Combustion Induced Vortex Breakdown. Combust. Sci. Technol., volume 179 (issue 7), 2007: 1385-1416.

Lefebvre A.H. Gas Turbine Combustion, Taylor \& Francis Group, New York, USA, 1999.

Lieuwen T., McDonnell V., Santavicca D., Sattelmayer T. Burner Development and Operability Issues Associated with Steady Flowing Syngas Fired Combustors, Combust. Sci. Technol., volume 180, 2008: 1169-1192.

Lucca-Negro O. and O'Doherty T. Vortex Breakdown: A Review, Prog. Energy Combust. Sci., volume 27 (issue 4), 2001: 431-481.

Nauert A., Petersson P., Linne M., Dreizler A. Experimental Analysis of Flashback in Lean Premixed Swirling Flames. Exp. Fluids, volume 43 (issue 1), 2007: 89-100.

Plee S.L. and Mellor A.M. Review of Flashback Reported in Prevaporizing/Premixing Combustors. Combust. Flame, volume 32, 1978: 193-203.

Sarpkaya T. On Stationary and Travelling Vortex Breakdown. J. Fluid Mech., volume 45 (issue 3), 1971: 545-559.
Subramanya M. and Choudhuri A. Investigation of Combustion Instability Effects on the Flame Characteristics of Fuel Blends, in: 5th Int. Energy Convers. Eng. Conf. Exhib. Proc. Ref. AIAA 2007-4796, 2007.

Syred N. A Review of Oscillation Mechanisms and the Role of the Precessing Vortex Core (PVC) in Swirl Combustion Systems, Prog. Energy Combust. Sci., volume 32 (issue 2), 2006: 93-161.

Syred N. and Beer J.M. Combustion in Swirling Flow: A Review, Combust. Flame, volume 23, 1974: 143-201.

Thornton J.D., Chorpening B.T., Sidwell T.G., Strakey P.A., Huckaby E.D., Benson K.J. Flashback Detection. Sensor for Hydrogen Augmented Natural Gas Combustion, in: Proc. ASME Turbo Expo, Ref. GT2007-27865, 2007.

Valera-Medina A., Syred N., Bowen P., Crayford A. Studies of Swirl Burners Characteristics, Flame Lengths and Relative Pressure Amplitudes, ASME J. Fluids Eng., volume 133 (issue 10), 2011, doi:10.1115/1.4004908.

Valera-Medina A., Syred N., Griffiths A.J. Visualization of Isothermal Large Coherent Structures in a Swirl Burner. Combust. Flame, volume 156 (issue 9), 2009: 1723-1734.

Valera-Medina A. Coherent Structures and their Effects on Processes Occurring in Swirl Combustors, (PhD Thesis), Cardiff University, Wales, UK, 2009.

Vigueras-Zuniga M.O., Valera-Medina A., Syred N. Studies of the Precessing Vortex Core in Swirling Flows. Journal of Applied Research and Technology, volume 10 (issue 5), 2012: 755-765.

\section{Citation for this article:}

Chicago citation style

Vigueras-Zúñiga, Marco Osvaldo, Agustín Valera-Medina, Nicholas Syred, Daniel De La Rosa-Urbalejo. Flashback Avoidance in Swirling Flow Burners. Ingeniería Investigación y Tecnología, XV, 04 (2014): 603-614.

\section{ISO 690 citation style}

Vigueras-Zúñiga M.O., Valera-Medina A., Syred N., De La RosaUrbalejo D. Flashback Avoidance in Swirling Flow Burners. Ingeniería Investigación y Tecnología, volume XV (issue 4), October-December 2014: 603-614. 


\section{About the authors}

Marco Osvaldo Vigueras-Zúñiga. Mechanical engineer from UNAM, obtained his MSc in project management and his $\mathrm{PhD}$ in thermofluids for turbomachinery at Cranfield University, England. He is responsible for the energy-thermofluid research group at the Universidad Veracruzana and has the role of leader in numerical simulation in combustion technologies. He is also consultant for research projects in the fields of oil and gas, energy and aerospace. He has various publications with national and international journals, as well as several research thesis.

Agustín Valera-Medina. Mechanical engineer from the UNAM, obtained his MSc in geoenvironmental engineering and $\mathrm{PhD}$ in combustion dyanmics at Cardiff University, Wales. After working for a research centre in Mexico, CIATEQ, he moved back to the UK to continue his research in combustion dynamics and thermofluids for gas turbines. Now, he is a lecturer at Cardiff University, involved in the topics of propulsion, combustion, alternative fuels and thermoacoustics. He has participated in several international conferences, with more than 30 publications. Some of the latter have been written for journals such as Combustion and Flame, Experiments in Fluids, ASME, AIAA, etc.

Nicholas Syred. Mechanical engineer from Sheffield, he obtained his doctoral degree in 1969 in power fluids, getting a position as associate researcher in the department of swirling flows under the tutelage of Prof. Chigier and Prof. Beer. He moved to Cardiff in 1974, where he has conducted a great variety of projects with BP, Air Products, SERC, UKAEA, etc. In 2002, he was awarded the NATO prize for innovation in cooling systems for gas turbine blades. Currently, he is a fellow of the IMechE. He has published more than 300 papers, giving supervision to more than 30 students at $\mathrm{PhD}$ level.

Daniel de la Rosa-Urbalejo. Industrial engineer from the UNAM, he worked for 4 years in the aerospace industry. He was awarded a scholarship for his MSc in mechanical engineering at the Faculty of Engineering, UNAM. After completing his degree, he was awarded another scholarship to continue his studies at Cardiff University, obtaining a $\mathrm{PhD}$ in flame stretch and combustion fundamentals using alternative fuels. He has participated in 9 conferences across Europe and the United States, presenting 2 papers in the European combustion meeting and the turbo expo ASME. 